\title{
Attention to principles of exercise training: an updated systematic review of randomized controlled trials in cancers other than breast and prostate
}

Kelcey A. Bland', Sarah E. Neil-Sztramko², Kendra Zadravec ${ }^{3}$, Mary E. Medysky ${ }^{4}$, Jeffrey Kong ${ }^{5}$, Kerri M. Winters-Stone ${ }^{4}$ and Kristin L. Campbell ${ }^{3,5^{*}}$

\begin{abstract}
Background: The primary objective of this systematic review was to update our previous review on randomized controlled trials (RCTs) of exercise in cancers other than breast or prostate, evaluating: 1) the application of principles of exercise training within the exercise prescription; 2) reporting of the exercise prescription components (i.e., frequency, intensity, time, and type (FITT)); and 3) reporting of participant adherence to FITT. A secondary objective was to examine whether reporting of these interventions had improved over time.

Methods: MEDLINE, EMBASE, CINAHL and SPORTDiscus databases were searched from 2012 to 2020. Eligible studies were RCTs of at least 4 weeks of aerobic and/or resistance exercise that reported on physiological outcomes relating to exercise (e.g., aerobic capacity, muscular strength) in people with cancer other than breast or prostate.

Results: Eighty-six new studies were identified in the updated search, for a total of 107 studies included in this review. The principle of specificity was applied by $91 \%$, progression by $32 \%$, overload by $46 \%$, initial values by $72 \%$, reversibility by $7 \%$ and diminishing returns by $5 \%$. A significant increase in the percentage of studies that appropriately reported initial values ( 46 to $80 \%, p<0.001$ ) and progression ( 15 to $37 \%, p=0.039$ ) was found for studies published after 2011 compared to older studies. All four FITT prescription components were fully reported in the methods in $58 \%$ of all studies, which was higher than the proportion that fully reported adherence to the FITT prescription components in the results (7\% of studies). Reporting of the FITT exercise prescription components and FITT adherence did not improve in studies published after 2011 compared to older studies.

Conclusion: Full reporting of exercise prescription and adherence still needs improvement within exercise oncology RCTs. Some aspects of exercise intervention reporting have improved since 2011, including the reporting of the principles of progression and initial values. Enhancing the reporting of exercise prescriptions, particularly FITT adherence, may provide better context for interpreting study results and improve research to practice translation.
\end{abstract}

Keywords: Neoplasms, Oncology, Exercise prescription, Resistance training, Aerobic exercise

\footnotetext{
* Correspondence: kristin.campbell@ubc.ca

${ }^{3}$ Rehabilitation Sciences, University of British Columbia, Vancouver, British Columbia, Canada

${ }^{5}$ Department of Physical Therapy, University of British Columbia, 212-2177

Wesbrook Mall, Vancouver, BC V6T 1Z3, Canada

Full list of author information is available at the end of the article
}

\section{$\triangle B M C$}

(c) The Author(s). 2021, corrected publication 2021. Open Access This article is licensed under a Creative Commons Attribution 4.0 International License, which permits use, sharing, adaptation, distribution and reproduction in any medium or format, as long as you give appropriate credit to the original author(s) and the source, provide a link to the Creative Commons licence, and indicate if changes were made. The images or other third party material in this article are included in the article's Creative Commons licence, unless indicated otherwise in a credit line to the material. If material is not included in the article's Creative Commons licence and your intended use is not permitted by statutory regulation or exceeds the permitted use, you will need to obtain permission directly from the copyright holder. To view a copy of this licence, visit http://creativecommons.org/ licenses/by/4.0/. The Creative Commons Public Domain Dedication waiver (http://creativecommons.org/publicdomain/zero/1. 0/) applies to the data made available in this article, unless otherwise stated in a credit line to the data. 


\section{Introduction}

The number of randomized controlled trials (RCTs) evaluating the role of exercise in an oncology setting has risen sharply. Accumulating evidence suggests exercise can be prescribed as an adjunct therapy to manage the acute and long-term adverse effects of anticancer therapies and improve overall health and survivorship after a cancer diagnosis $[1,2]$. While initial research in exercise oncology confirmed these benefits primarily in women with early-stage breast cancer [3-5], followed by men with prostate cancer [6-8], the past decade has seen a surge in RCTs demonstrating similar benefits in numerous other cancer types [2], as well as in advanced cancer and in the palliative care setting $[9,10]$.

Within the field of exercise oncology, a new appreciation for greater precision in prescribing exercise has emerged, with the aim to optimally target specific patient symptoms and health needs [11-14]. An exercise intervention for individuals with cancer can be prescribed or "dosed" to enhance its efficacy, which can be accomplished through the application of well-established exercise training principles: specificity, progression, overload, initial values, reversibility and diminishing returns (Table 1). For example, in a study exploring the effect of exercise on aerobic capacity, enrolling participants who report low baseline levels of moderate-to-vigorous physical activity or who are actively undergoing therapies associated with reductions in aerobic capacity would meet the principle of initial values, as such participants are more likely to benefit from an aerobic exercise intervention.
Once the prescription has been designed based on these principles of training, the delivery of the prescription is operationalized by the appropriate manipulation of the "FITT" exercise formula: Frequency, Intensity, Time, and Type. Adequate exercise intervention replication or translation into a "real-world" setting requires clinical trials to report these FITT prescription components in the planned exercise prescription, along with participant adherence to each FITT prescription component. This allows for clarity on the exercise dose prescribed and the actual dose received, which oftentimes can differ based on variability in the tolerance of the study sample to the prescribed program. Failing to consider differences in adherence rates to an exercise intervention could result in drawing false conclusions about efficacy of a specific exercise prescription. Adhering to the principles of exercise training and use of FITT for prescription and adherence recording avoids mistakenly drawing conclusions that are due to poor intervention design, monitoring, or reporting, versus a lack of a true effect.

Our group first published two systematic reviews in 2012 and 2014 that summarized the utilization of the exercise training principles and associated adherence outcomes in a total of 29 RCTs in women with breast cancer [15] and 33 RCTs in all other cancer types [16]. We concluded that most exercise training principles were inconsistently incorporated within studies and adherence to the FITT prescription components was rarely adequately reported. This conclusion, along with the exponential increase in published exercise oncology RCTs

Table 1 Principles of exercise training

\begin{tabular}{lll}
\hline Principle & Criteria for this review & Example \\
\hline $\begin{array}{l}\text { Specificity: Training adaptations are specific to } \\
\text { the organ system or muscles trained with }\end{array}$ & $\begin{array}{l}\text { Appropriate population targeted and } \\
\text { exercise }\end{array}$ & $\begin{array}{l}\text { Aerobic exercise such as brisk walking is more } \\
\text { outcome }\end{array}$ \\
appropriate for an intervention aimed at & $\begin{array}{l}\text { increasing cardiovascular fitness than strength } \\
\text { training }\end{array}$ \\
Progression: Over time, the body adapts to & Stated exercise program was progressive and & Increase duration of walking program by 5\% every
\end{tabular}

exercise. For continued improvement, the volume or intensity of training must be increased outlined training progression

2 weeks depending on exercise tolerance

Overload: For an intervention to improve fitness, the training volume must exceed current habitual physical activity and/or training levels

Initial values: Improvements in the outcome of interest will be greatest in those with lower initial values

Rationale provided that program was of

removed, fitness levels will eventually return to baseline

Diminishing returns: The expected degree of improvement in fitness decreases as individuals become more fit, thereby increasing the effort required for further improvements. Also known as the 'ceiling effect' sufficient intensity/exercise prescribed relative to baseline capacity

Selected population with low level of primary outcome measure and/or baseline physical activity levels

Performed follow-up assessment on participants who decreased or stopped exercise training after conclusion of intervention

Prescribing intensity in a resistance training program based on $\%$ of measured and/or estimated 1-repetition maximum

Selecting a sample with high baseline fatigue levels to participate in an aerobic training program to increase cardiovascular fitness and reduce fatigue

Participants who maintained training after a supervised exercise program preserved strength whereas those who stopped exercising returned to baseline

Performed follow-up assessment of primary outcomes on participants who continued to exercise after conclusion of intervention
Gains in muscle strength are greatest in the first half of a training program unless the training stimulus continually increases 
in the past decade, prompted our group to update our previous reviews in breast cancer [17] and prostate cancer [18] to track the field's progress in this area. Given a major shift in the focus towards evaluating the role of exercise across a diverse range of cancer types and treatments, this updated systematic review summarizes the literature to-date in all other cancer types (namely, cancers other than breast and prostate). In this updated review, our primary aim was to evaluate: 1 ) the use of the principles of exercise training in the design of the exercise prescription; 2) the reporting of the FITT exercise prescription components in the study methods; and 3) the reporting of participant adherence to the FITT prescription components in the study results. A secondary aim was to explore whether any improvement in reporting on the principles of exercise training and FITT exercise prescription components and adherence had occurred since our last publication.

\section{Methods}

This systematic review followed the same protocol reported previously [15-18]. A search of MEDLINE, CINAHL, SPORTDiscus and EMBASE databases was conducted with dates ranging from January 1, 2012 to September 23, 2020, following up on the last search conducted from 1990 to December 31, 2011. Studies that included participants with any cancer diagnosis other than prostate cancer from our previously published review [16] were also included in this review. The search terms, as previously used, included cancer (neoplasm, carcinoma) and exercise (physical activity, aerobic, resistance, walking) specified for each database, in combination with the AND term. Only English-language publications were included. Other relevant systematic reviews were manually searched for relevant publications for inclusion. The protocol was not registered, as our original review [16] commenced prior to the launch of PROSPERO. Because the protocol is already published, we did not register this updated review.

Eligibility criteria included: 1) RCTs with one or more arms involving at least 4 weeks of aerobic and/or resistance exercise; 2) reported one physiological outcome related to exercise (e.g., aerobic capacity, muscular strength, physical function, body composition); and 3) included patients with a cancer diagnosis other than only breast or prostate. The criteria of a minimum 4 weeklong exercise intervention and reporting on physiological outcomes relating to exercise were not applied in our original 2014 review [16]. As a result, studies included in our 2014 review that did not meet these updated criteria were excluded from the current analysis. Exclusion criteria included: 1) alternative forms of exercise (e.g., yoga, tai chi) or complimentary alternative methods (i.e., physical therapy, stretching); 2) studies that only included patients with metastatic or incurable cancer diagnoses (e.g., inoperable lung cancer); and 3) studies that focused on prehabilitation (i.e., exercise exclusively prior to surgery), or physical activity and/or nutrition behaviour change.

Four reviewers (KB, KZ, MM and SNS) independently determined eligibility using an online software system (Covidence Systematic Review software, Veritas Health Innovation, Melbourne, Australia). Article titles and abstracts were screened for study eligibility and full-text versions of relevant papers were then reviewed to determine eligibility. Discrepancies were discussed and resolved by the input of a senior team member (SNS, KWS, and KC), as required. Reviewers independently extracted relevant data using the online software system (KB, KZ, MM and JK), followed by a discussion and resolution of discrepancies between reviewers or by a third reviewer (SNS, KWS, and KC). Data extraction included: cancer type, sample size, timing of intervention delivery (during or after cancer treatment), treatment type, intervention duration and mode of delivery (supervised or home-based), timing of follow-up measures, primary outcomes, secondary physical fitness and physiological outcomes, and reported study findings. "FITT" (frequency of sessions per week, relative or absolute intensity of exercise, time (duration) of exercise, and type of exercise) was used to summarize the exercise prescription. Participant adherence to each FITT prescription component was also extracted where reported by study authors.

For all exercise training principles, reporting of FITT prescription components, and reporting of participant adherence to FITT prescription components, reviewers independently allocated a rating system where a ' + ' was assigned when the outcome was comprehensibly reported, a 'NR' was assigned when the outcome was not reported in the exercise prescription, and a '?' was assigned when the outcome was mentioned but the description was unclear and would not allow for intervention replication. These ratings were also applied to the reporting of participant adherence to the prescription. All available publications and supplementary files were reviewed for a given study to determine ratings. For multi-arm trials, the training principles were considered separately for each intervention arm. For RCTs included in our previous 2014 review across all cancer types [16], if new publications from the same study or data set were identified, ratings were updated in the present review, if more information was available in the newer publication. In line with the methods described in our other updated reviews $[17,18]$, we report frequencies and percentages of studies meeting the criterion for each training principle, FITT prescription component, and participant adherence to each FITT prescription component. 
To determine whether there had been an improvement in the reporting of each exercise training principle, FITT prescription components, and adherence to FITT components since our original search for our previous review [16], a chi-square test was used to calculate the difference in the number of studies reporting ' + ' versus '?' or 'NR' in studies published after 2011 compared to older studies.

\section{Results}

The flow chart of search results and study selection process is shown in Fig. 1. A total of 127 new manuscripts, describing 86 studies were identified in our updated search. Of the 33 studies included in the last review, five studies were not included in the current review's analysis as they did not meet our updated inclusion criteria of a four week minimum intervention [19-22] and reporting on physiological outcomes relating to exercise [23]. Three previous studies [24-26] had a total of seven additional papers published after the original search [27-33]. Upon reviewing newly published manuscripts for previous studies, no changes to the study ratings were made. The results for seven prostate cancer studies from our previous 2014 review were included in a separate updated review specifically in prostate cancer studies [18]. Thus, a total 107 studies, with 122 distinct intervention arms, were included in the final analysis.

A comprehensive description of all evaluated studies, including patient population, sample size, intervention, and outcome measures, is provided in Supplementary File 1 . There were 58 (54\%) studies conducted among adults diagnosed with solid tumours [24, 34-90], 25 (23\%) studies in haematological cancers [25, 91-114] and $24(22 \%)$ studies including patients with mixed cancer diagnoses [26, 115-137]. For the studies in solid

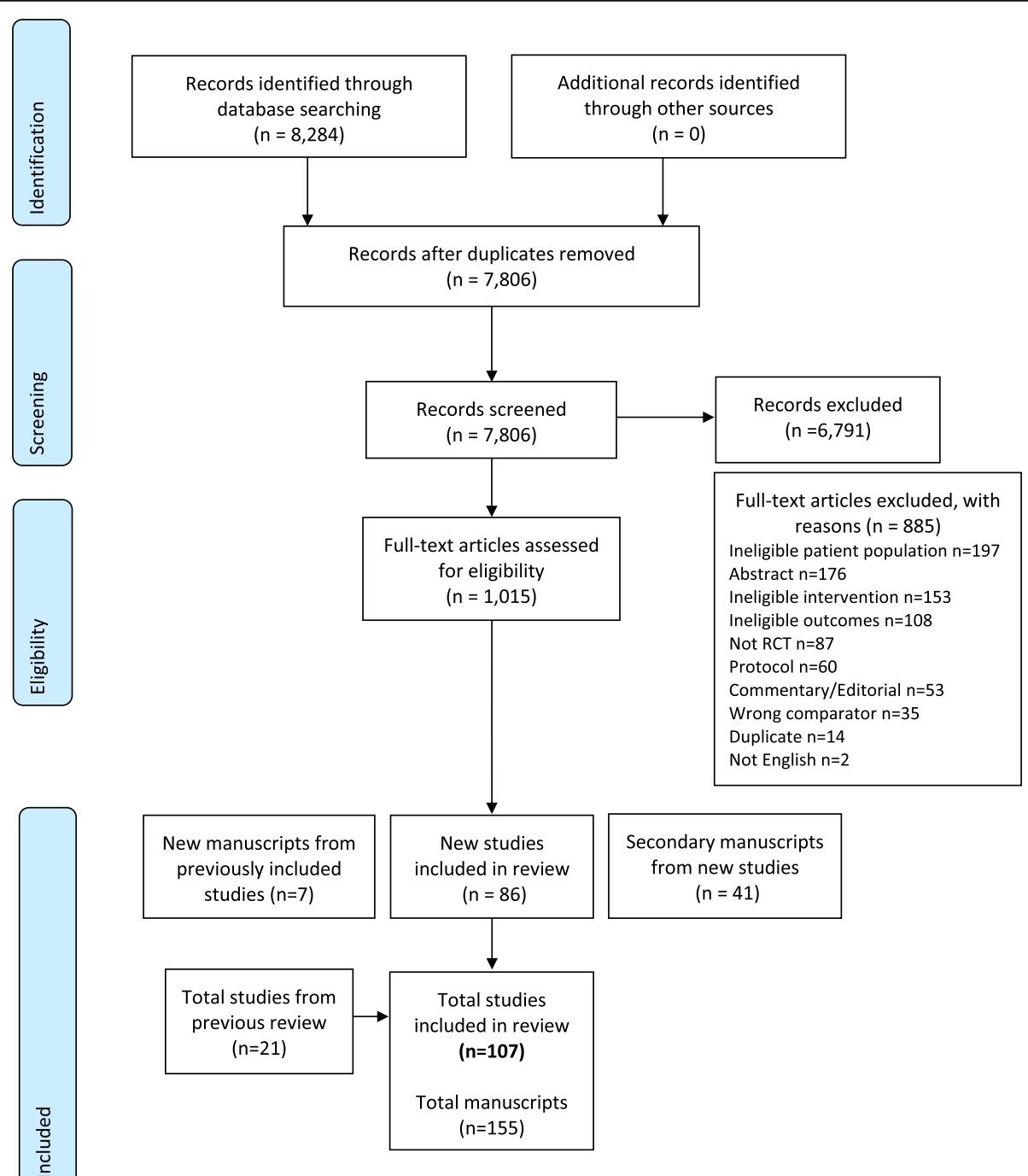

Fig. 1 PRISMA flow diagram 
tumours, exercise interventions were delivered during cancer treatment in 20 (34\%) studies [34-53], during and after treatment in 12 (21\%) studies [24, 54-64], and entirely after treatment in 26 (45\%) studies [65-90]. The most common solid tumour groups investigated were cancers of colon or rectum $(n=15,26 \%)$, lung $(n=12$, $21 \%)$, and head and neck $(n=10,17 \%)$. For studies in haematological cancers, 13 (52\%) delivered exercise interventions during treatment [91-103], specifically stemcell transplant or chemotherapy, four (16\%) during and after treatment [25, 104-106] and eight (32\%) after treatment [107-114]. In studies that enrolled adults with mixed cancer diagnoses, seven $(29 \%)$ of these studies delivered interventions during cancer treatment [26, 115-120], six (25\%) during and after treatment [121-126], and 11 (46\%) after treatment [127-137].

\section{Application of the principles of exercise training}

Ratings for the application of the exercise training principles for all studies and intervention arms, categorized by tumour and treatment type, are shown in Table 2 . Differences in the reporting of training principles by study publication year are depicted in Fig. 2A. Only two studies fully reported and applied all six training principles to their interventions. Full application and reporting of at least half of the training principles (i.e., three out of a total six) was found for 53 (49\%) studies in total. Five (4\%) studies did not adequately report applying any of the six training principles.

Specificity was the most frequently applied training principle and appropriately reported in 97 (91\%) studies. Given specificity was commonly adequately applied across all studies, no significant difference in the reporting of specificity was found among new studies published after 2011 compared to older studies $(91 \%$ vs. $88 \%$; $p=$ 0.659). The principle of initial values was the second most applied training principle and was appropriately reported in 77 (72\%) studies overall. A significant improvement in the reporting of initial values was found for new studies published after 2011 compared to older studies $(80 \%$ vs. $46 \%, p<0.001)$. Progression was appropriately reported and applied in 34 (32\%) studies. Like initial values, appropriate reporting of progression also improved in new studies published after 2011 compared to older studies $(37 \%$ vs. $15 \%, p=0.039)$. The principle of overload was appropriately applied and reported in 49 (46\%) studies in total. While the number of studies adequately reporting overload increased in new studies compared to older ones, this difference was not statistically significant $(49 \%$ vs. $35 \%, p=0.189)$. Most studies did not adequately report or unclearly reported the principles of reversibility and diminishing returns. Reversibility was only appropriately applied in 7 (7\%) studies overall, all of which were new studies published after
2011. Reporting of reversibility was not significantly different between new and older studies ( $7 \%$ vs. $0 \%, p=$ 0.121). Diminishing returns was appropriately reported in $5(5 \%)$ studies overall and no difference in the reporting of diminishing returns was found between new and older studies ( $4 \%$ vs. $8 \%, p=0.402)$.

\section{Reporting of the FITT prescription components}

Ratings for the reporting of the FITT exercise prescription components for all studies and intervention arms are shown in Table 2. Differences in the reporting of the FITT prescription components between new studies published after 2011 compared to older studies is depicted in Fig. 2B. All four FITT prescription components were reported in full within the study methods in 62 out of 107 (58\%) studies. There were 97 (91\%) studies that fully reported at least half of the FITT prescription components (i.e., at least two out of four). Only two (2\%) studies did not fully report any of the four FITT prescription components in the study methods.

The prescribed exercise session frequency (i.e., days per week) was the most frequently fully reported FITT prescription component and was reported in 99 (93\%) studies overall. There was no difference in the reporting of frequency between new studies published after 2011 compared to older studies ( $93 \%$ vs. $92 \%, p=0.962)$. The prescribed target exercise intensity was fully reported in 77 (72\%) studies, with no difference in reporting between new studies published after 2011 and older studies (70\% vs. $77 \%, p=0.518)$. A target exercise duration, or time, was fully reported for 90 (84\%) studies overall and no difference in the reporting of the prescribed exercise time was found between new studies and older studies ( $85 \%$ vs. $85 \%, p=0.936$ ). Lastly, the prescribed exercise type was fully reported for 89 (83\%) studies overall. Similarly, there was no difference in the reporting of exercise type between new studies and older studies (80\% vs. $92 \%, p=0.153)$.

\section{Reporting of FITT prescription adherence}

Ratings for the reporting of participant adherence to the FITT exercise prescription components for all studies and intervention arms are shown in Table 2 . Full reporting of adherence to the FITT prescription components within the study results is shown for new studies published after 2011 compared to older studies in Fig. 2C. In total, adherence to all four FITT prescription components was reported in the study results for 8 out of 107 (7\%) total studies. Adherence to at least half of the FITT prescription components was reported in 31 (29\%) studies. There were 33 (31\%) studies that did not fully report adherence to any FITT prescription component. All evaluated studies appeared to be much more likely to fully 


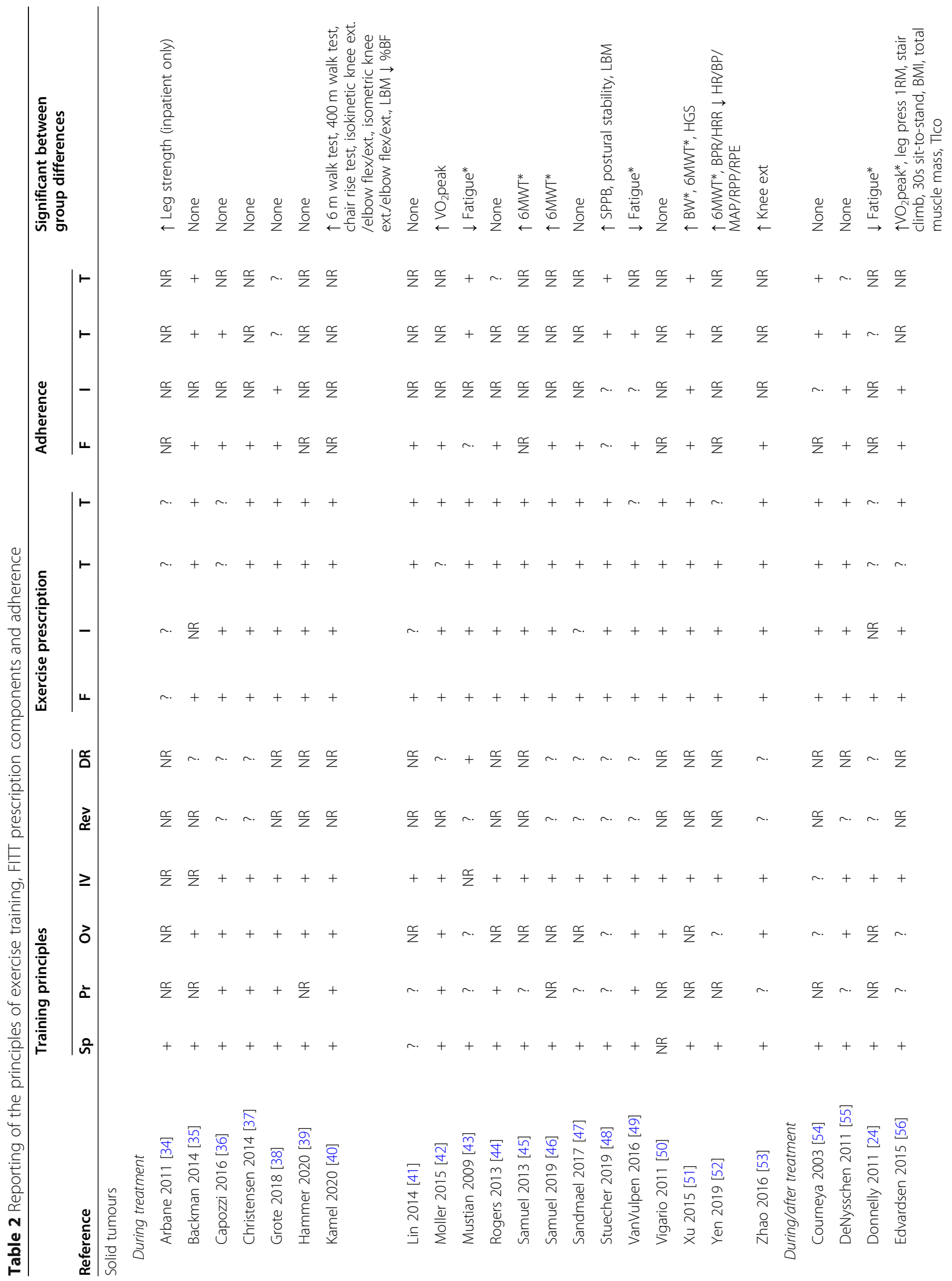




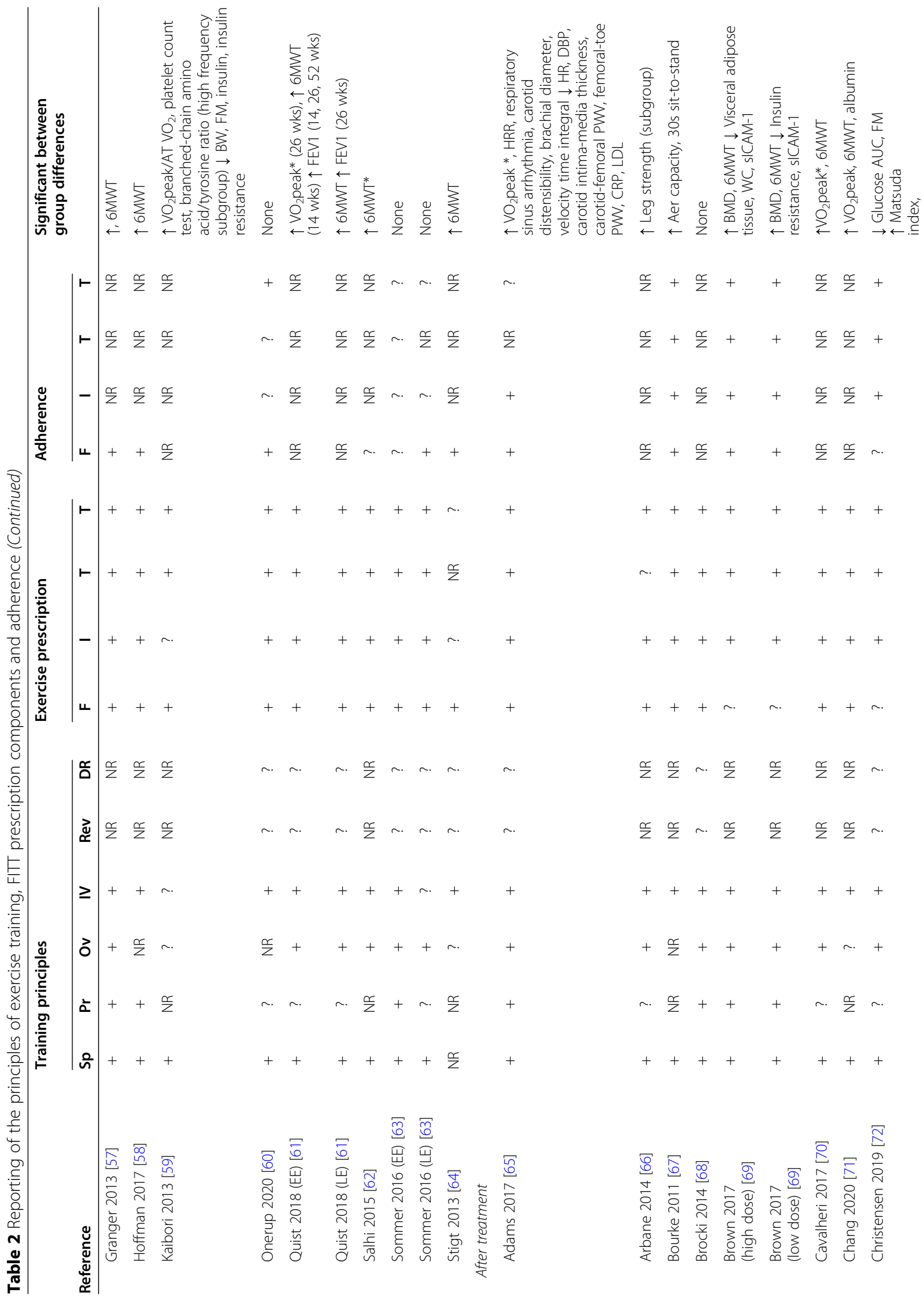




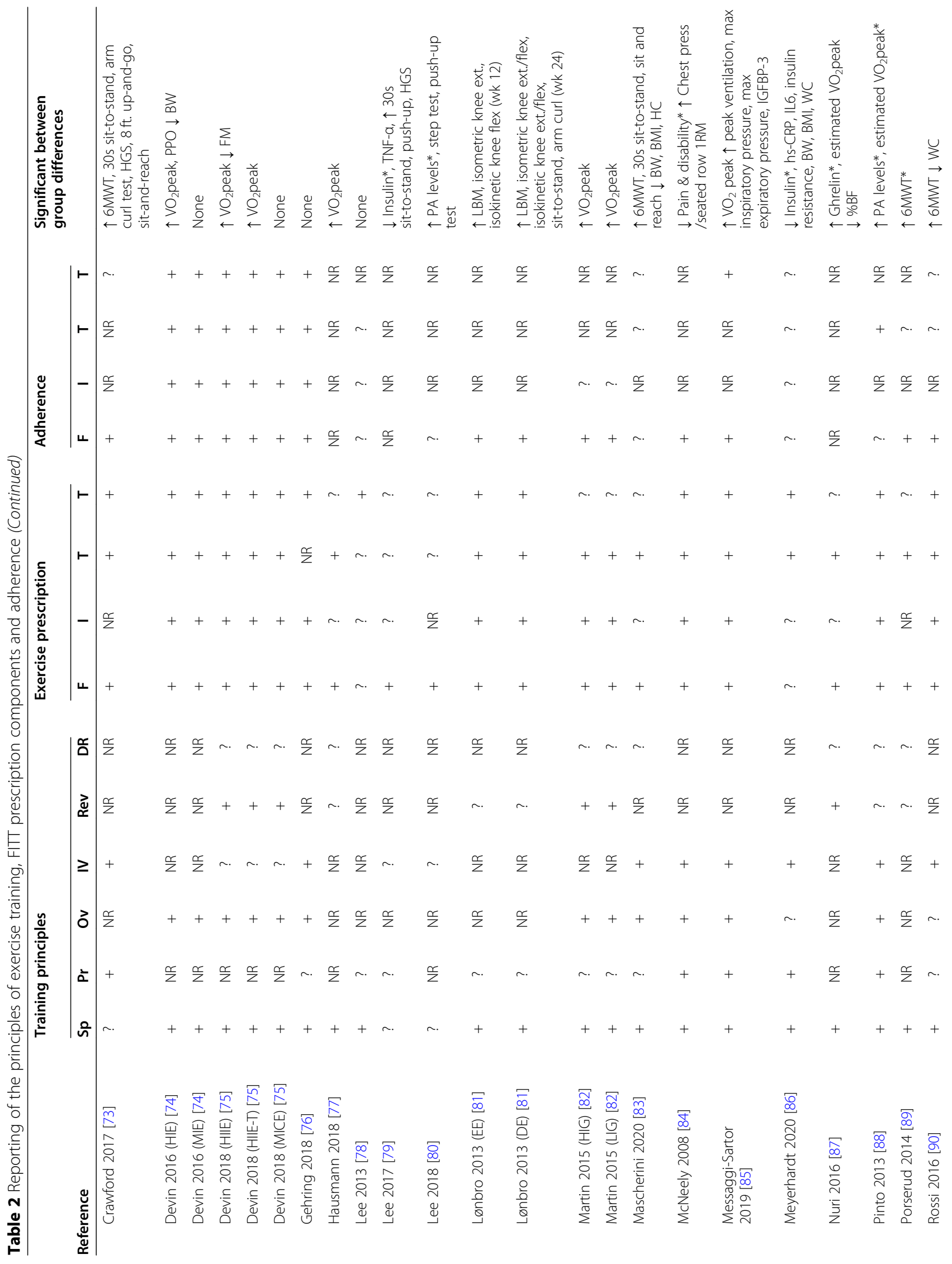




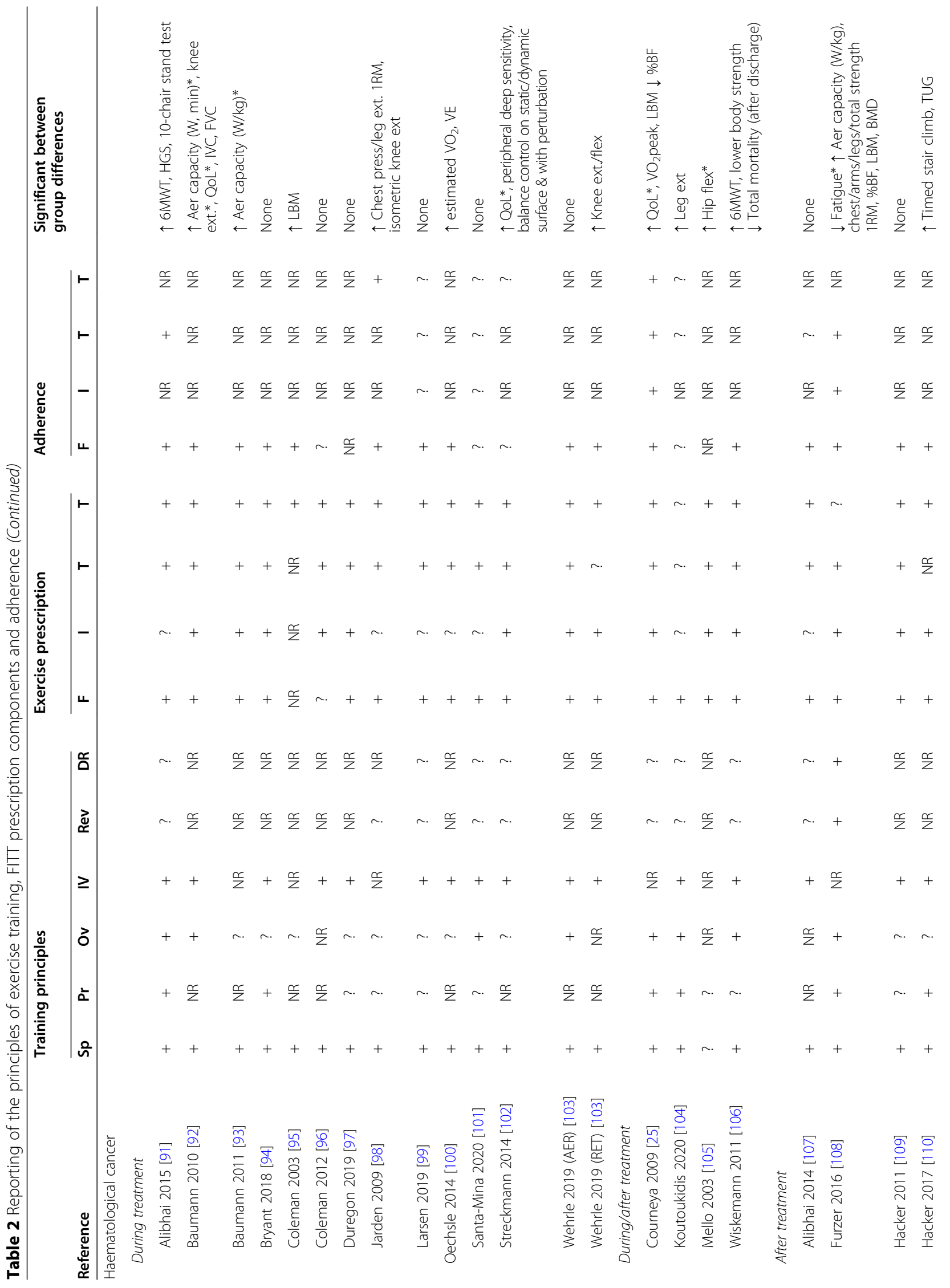




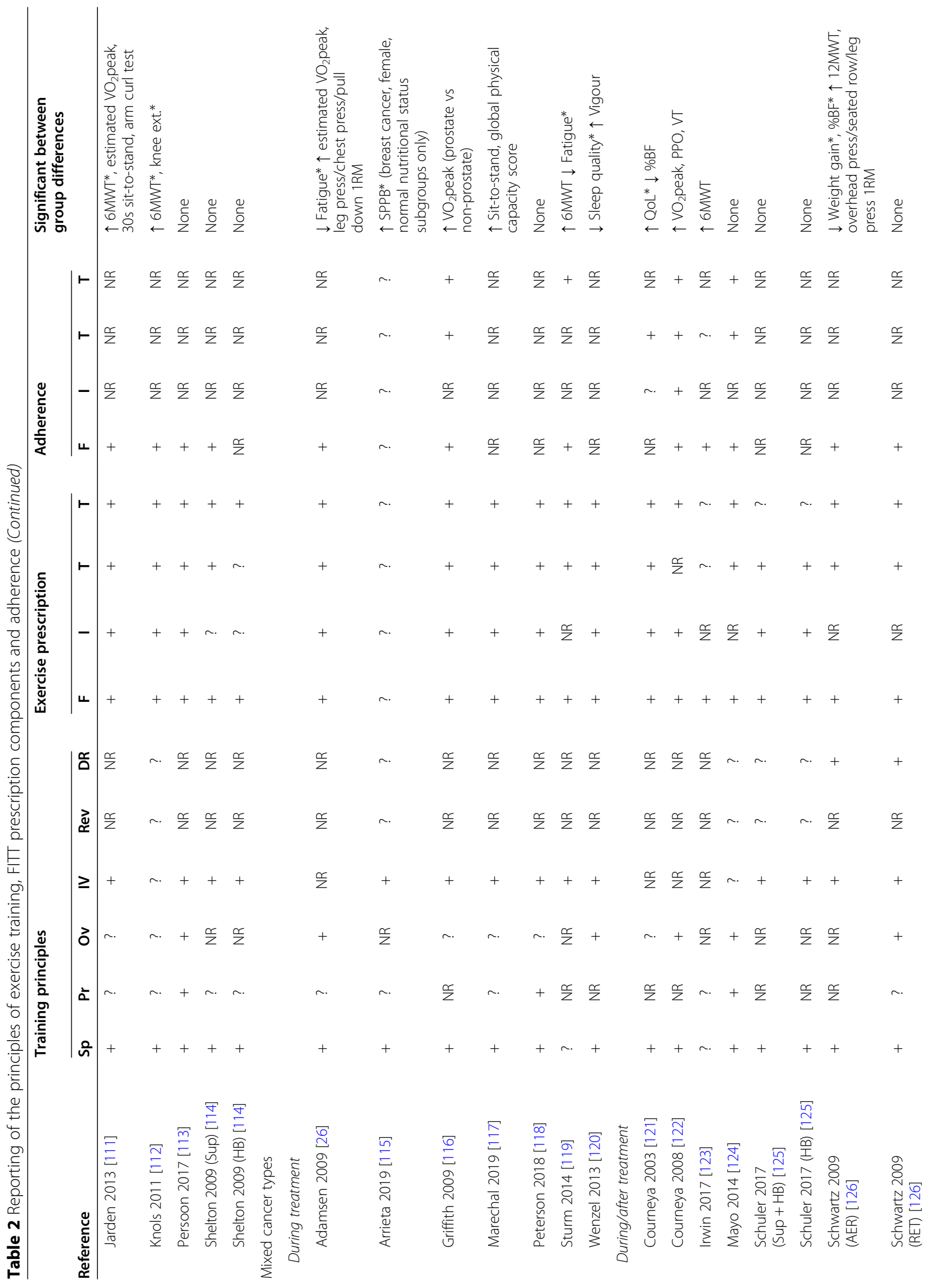




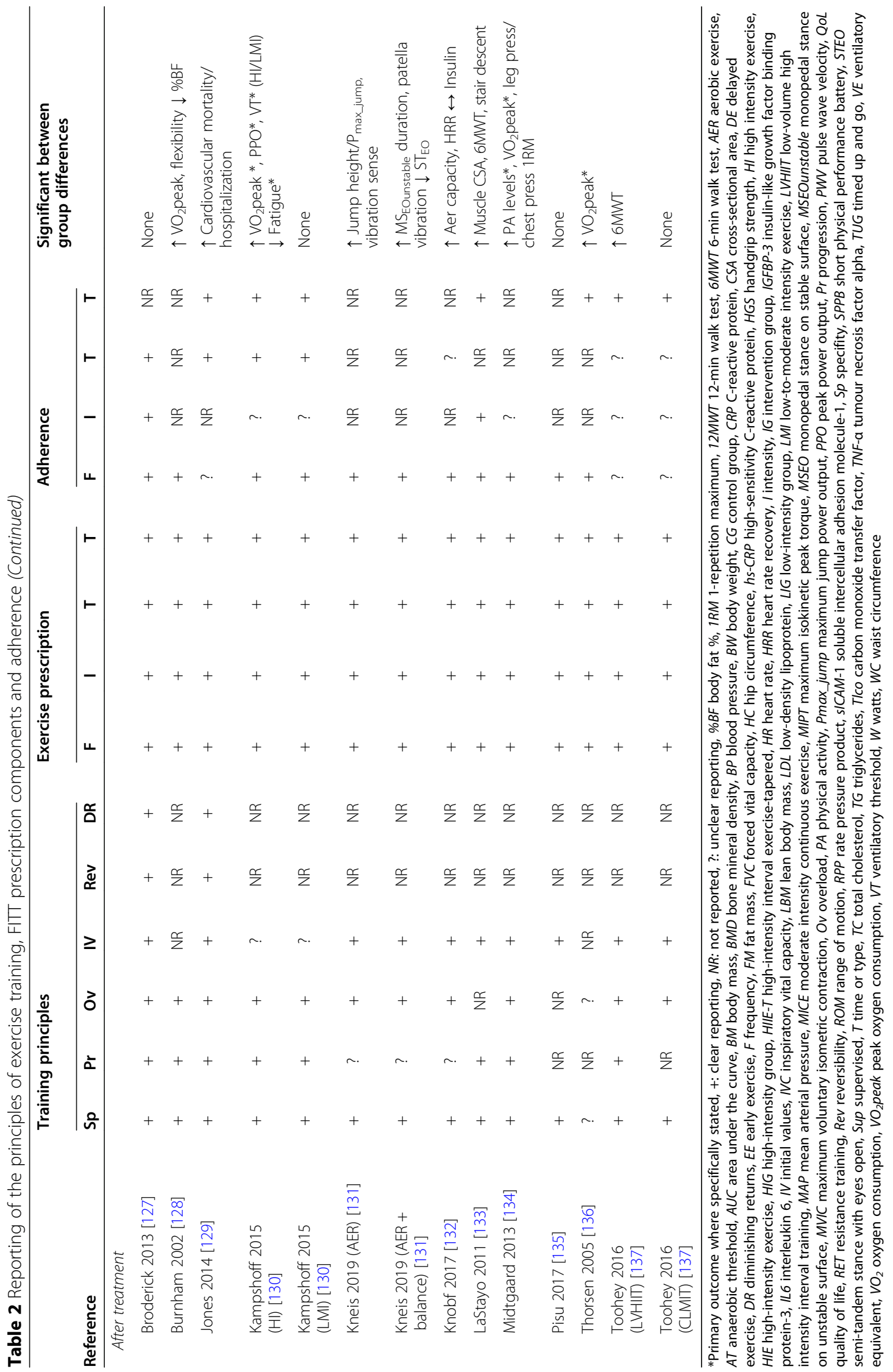


A) Exercise Training Principles

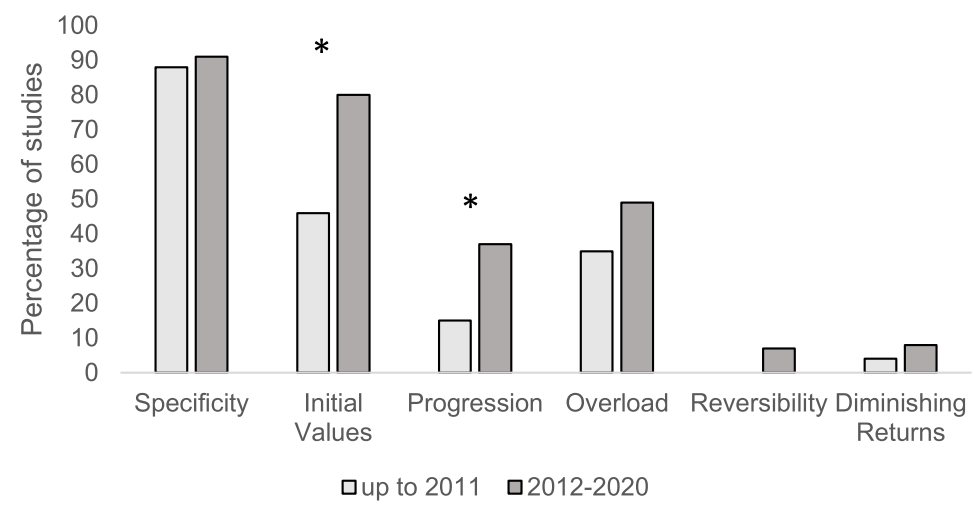

B) FITT Prescription Components

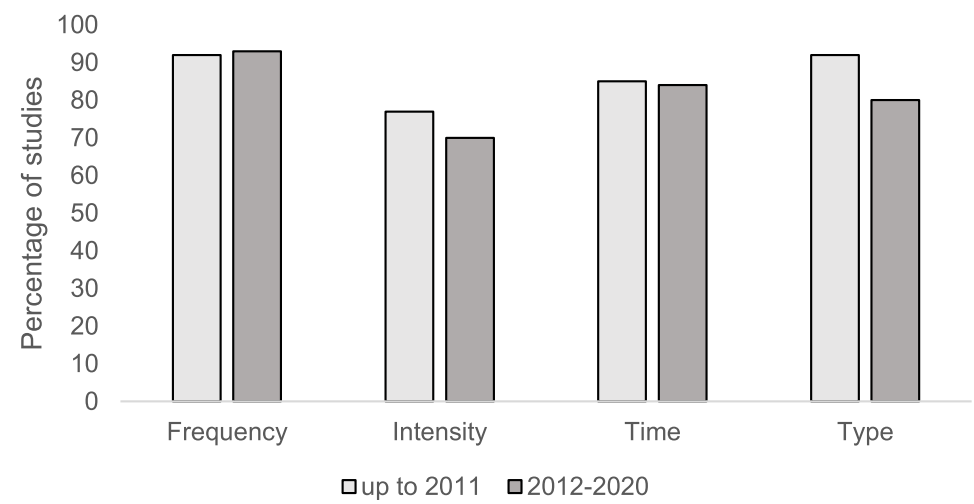

C) FITT Adherence

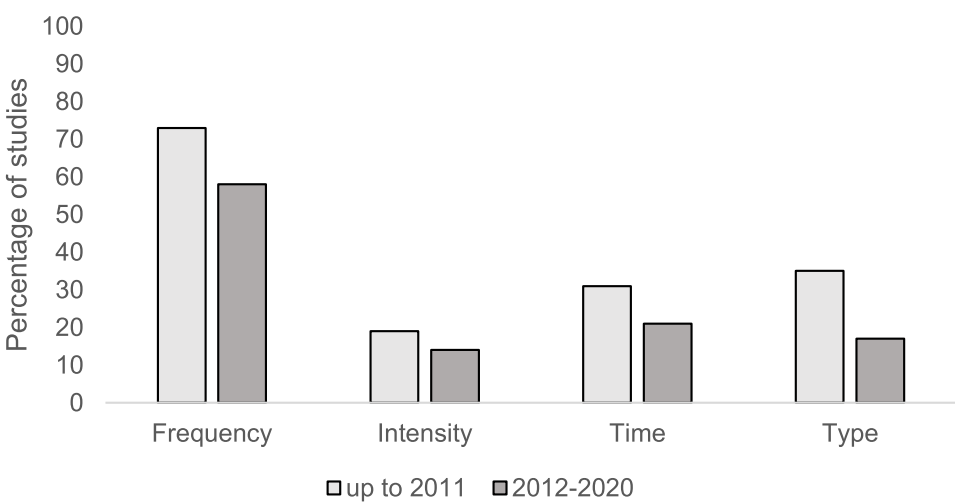

Fig. 2 Full Reporting of A) Exercise Training Principles, B) FITT Prescription Components and C) Adherence to FITT Prescription Components. Percentage of studies published between 2012 and 2020 compared to studies published up to 2011 that fully reported ' + ' each outcome. *Significant difference in the percentage of studies published between 2012 and 2020 compared to studies published up to 2011 that fully reported applying the principles of initial values and progression $(p<0.05)$. No significant difference in the reporting of FITT prescription components or adherence to FITT prescription components

report all four FITT prescription components in the study methods (58\%) compared to adherence to all four FITT prescription components in the study results $(7 \%)$.
Adherence to exercise session frequency (i.e., attendance) was the most fully reported adherence outcome and was reported in 66 (62\%) studies overall. Among new studies published after 2011, only 58\% of studies 
fully reported adherence to exercise session frequency compared to $73 \%$ of older studies $(p=0.170)$. There was full reporting of exercise adherence to intensity for 16 (15\%) studies in total, with no difference between new studies and older studies ( $14 \%$ vs. $19 \%, p=0.482)$. Adherence to exercise time was fully reported for 25 (23\%) studies overall, with no difference between new studies and older studies ( $21 \%$ vs. $31 \%, p=0.305)$. Adherence to exercise type was fully reported in 23 (22\%) studies and there was no difference between new studies and older studies ( $17 \%$ vs. $35 \%, p=0.061)$.

\section{Discussion}

In this systematic review, which included data from participants diagnosed with solid tumours and haematological cancers, the overall application and reporting of the principles of exercise training, the FITT prescription components, and exercise adherence varied. Less than $50 \%$ of all evaluated studies applied at least half of the exercise training principles (i.e., three or more out of six). However, a significant improvement in the application and reporting of initial values (46 to 80\%) and progression (15 to 37\%) was found for studies published after 2011 compared to older studies. Regarding the FITT exercise prescription components, 58\% of all evaluated studies reported applying all four FITT prescription components in the study methods, yet a much smaller proportion ( $7 \%$ of studies) reported adherence to all four FITT prescription components in the study results. No significant improvements over time were observed in the reporting of the FITT exercise prescription components or adherence to the FITT prescription components.

In this review, specificity was the most consistently applied exercise training principle. Specificity requires selecting the exercise modality based on the primary outcome (i.e., to improve aerobic fitness, prescribe aerobic exercise, such as brisk walking). This application should continue to be strong in future trials. To apply the principle of specificity one step further, future research could strive to narrow in on the most appropriate modality of exercise to elicit a training effect. For example, brisk walking may help to improve aerobic fitness in some patients, but other aerobic exercise modalities might be more effective. The elliptical trainer, on the other hand, may allow participants to achieve higher exercise intensities, as it recruits both upper and lower body muscle groups. Almost 70\% of all interventions appropriately reported initial values and reporting of this principle improved significantly among studies published after 2011. The principle of initial values considers participants' baseline levels of the target outcome of interest (e.g., physical fitness levels), as improvements in the outcome of interest will be greatest in those with lower initial values. Adequate reporting of the principle of progression also improved among new studies $(22 \%$ increase). However, over two-thirds of all studies did not report progression or provided an unclear description of how exercise was progressed, so that interventions may be replicated (e.g., 5-10\% increase in heart rate maximum every 2 weeks for aerobic exercise). The principle of overload, which requires exercise to be prescribed based on baseline exercise testing, was less commonly applied, and did not improve in new studies. While studies may be limited by resources, funding, and personnel to conduct gold-standard assessments of physical fitness (e.g., cardiopulmonary exercise testing), submaximal exercise testing protocols or clinical measures of physical function can still be utilized to facilitate prescribing more appropriate exercise targets to participants. Consideration of reversibility and diminishing returns were the least frequently applied training principles. This is understandable given that a follow up fitness test after completing the intervention may not be done or reported in the primary manuscript. However, performing repeat testing in people who continue to exercise (diminishing returns) and people who discontinue exercise (reversibility) upon intervention completion can help underscore the importance of delivering an adequate exercise stimulus for continued improvement as well as identify the minimal effective exercise dose required to achieve and maintain exercise health benefits.

The FITT exercise prescription components (i.e., prescribed exercise) were consistently more fully reported than participant adherence to the FITT prescription components (i.e., completed exercise) among our evaluated studies. Regarding adherence outcomes, frequency was the most reported, often as attendance or number of exercise sessions completed. However, we cannot emphasize enough the importance of reporting adherence beyond exercise session attendance; especially in feasibility studies and studies that are delivering 'novel' exercise interventions, such as non-linear or high intensity exercise prescriptions, or focusing on understudied cancer populations. Reporting of adherence to exercise intensity and duration, or resistance training volume, can be challenging within studies. However, there are recent publications that are examples of exemplary exercise adherence reporting in oncology and can help guide future research $[13,14,138-140]$. These papers illustrate widespread variations or disruptions in exercise session attendance and prescription adherence among participants and throughout cancer treatment. For example, exercise session attendance and adherence to aerobic exercise was shown to gradually decrease over the course of chemotherapy for breast cancer and over a third of participants required aerobic exercise intensity adjustments due to treatment symptoms [13]. If this study did 
not report on adherence to the prescribed intensity of exercise, any practical application of this study in clinical settings could risk injuring patients or participant dropout. This data highlights the the necessity of adjusting to participant needs; especially during cancer treatment, when individuals present with cyclic changes in symptom severity between chemotherapy cycles and potentially, accumulating symptom severity as treatment duration lengthens. Less than perfect exercise adherence does not indicate study failure and full reporting of exercise prescription adherence should be considered a strength across exercise oncology RCTs. Adherence reporting and transparency is necessary for continued improvement in exercise intervention design as well as the development of evidence-informed approaches to modifying exercise dose for appropriate translation of RCT findings into clinic and community settings.

For some outcomes, we noted that the reporting of FITT prescription components and adherence trended towards being worse across new studies published after 2011 compared to earlier studies. Full reporting of the prescribed exercise type, for example, was seen in $80 \%$ of new studies published after 2011 compared to $92 \%$ of earlier studies. There are several possible explanations for this observation. Applying the FITT prescription components and reporting adherence is more complex for interventions that prescribe exercise outside of 'typical' aerobic or resistance-based training. One example is the study by Crawford et al. that prescribed a wallclimbing intervention to women who had undergone treatment for gynaecological cancer [69]. For this type of intervention, rating of perceived exertion (RPE) [141] and exercise minutes can still be collected as proxies for exercise intensity and duration. For home-based exercise interventions, specifically, many studies prescribed exercise duration as total minutes per week (e.g., $150 \mathrm{~min}$ per week of moderate to vigorous exercise) and then reported the total mean minutes per week completed for the intervention group. In addition to this, reporting how long the participants' mean duration was for a single bout of exercise would still be of value (adherence to exercise time) as well as the number of days participants chose to exercise per week (adherence to exercise frequency). Moreover, studies prescribing home-based exercise also frequently do not report the prescribed exercise type, as it may be self-selected by participants. Reporting some examples of "suggested" exercise types within the study methods, such as walking outside, would clarify the exercise prescription. Reporting the types of exercises participants self-select in the adherence section of results would then provide insight on participant exercise preferences and help inform achievable exercise recommendations in a clinical or community setting. Reporting exercise adherence to resistance training exercise, is also somewhat of a challenge, given there are several variables of interest (i.e., sets, repetitions, weight). For resistance exercise training, prescribing a target RPE and collecting patient-reported RPE following each exercise is a pragmatic approach to exercise prescription and adherence monitoring [142]. RPE helps gauge resistance training intensity and whether patients are achieving volitional fatigue. Training loads can then be adjusted or progressed accordingly to ensure an adequate training stimulus is being applied. Moreover, Fairman et al. have recently provided guidance on how to clearly report adherence to resistance training in exercise oncology [138].

Outside of the exercise oncology literature, it has been shown that completeness or adequacy of intervention reporting is lower in non-pharmacological trials versus pharmacological trials [143]. For all clinical trials, full reporting of a given intervention is essential and goes beyond naming the intervention and listing its main components. There are crucial features of an intervention, including its setting, duration, mode of delivery, monitoring and so forth, which must be adequately described to allow for full intervention interpretation, replication, and implementation. Completeness reporting of exercise oncology trials according to TIDieR (template for intervention description and replication) checklist, for example, has been calculated as ranging from 46 to 96\% [144]. The TIDieR checklist contains 12 items: name, why, what (materials), what (procedure), who provided, how, where, when and how much, tailoring, modifications, how well (planned), how well (actual) [145]. We argue that in addition to standard completeness reporting for clinical interventions, as outlined in tools such as the TIDieR checklist, reporting of the exercise training principles and adherence, as discussed in this review, is necessary in exercise oncology for intervention replication and translation. To adopt this approach to study reporting, following the Consensus on Exercise Reporting Template (CERT) guidelines is recommended [146]. CERT highlights how to report frequency, intensity, duration and type of exercise outlined in section 13, "When, How Much" and exercise completed in section 16, "How Well: Planned, actual".

\section{Limitations}

We did not contact authors for missing information. Interventions may have been designed in line with the principles of exercise training, yet were perhaps not reported this way. Strict journal page limits can be a barrier to full reporting of exercise interventions. Online appendices and supplementary materials, however, can be used to report this information. Further, we did not include single-arm studies, studies in patients with incurable cancer or receiving palliative care, or studies with prehabilitation interventions, alternative exercise 
(e.g., yoga), physical therapy interventions (e.g., arm rehabilitation and mobilization following breast cancer surgery), or interventions less than 4 weeks. Evaluating the exercise intervention design and adherence for these special cases is likely still valuable and should be considered in future reviews. However, a recent review by Medysky et al. summarizes the reporting of exercise training principles in RCTs of lung cancer and includes both prehabilitation interventions and patients with incurable disease [147]. While we evaluated the application and reporting of exercise training principles, understanding how the application of these principles directly influences fitness and cancer-specific outcomes is an important area for ongoing research. A previous review evaluated how prescribed FITT factors moderated change in physical fitness in those living with and beyond cancer and found that greater exercise frequency and longer session duration resulted in larger effects [148]. Expanding this to include adherence to FITT and the application of the principles of exercise training will help pinpoint which intervention components should receive the greatest consideration in oncology settings.

\section{Conclusion}

With the growing number of exercise oncology trials conducted in a variety of cancer populations every year, appropriate application of the basic principles of exercise training highlighted in the current review is strongly encouraged. Since our previous reviews on this topic, we found that most exercise training principles are still inconsistently reported. However, we did find a significant improvement in the reporting of the principles of initial values and progression among studies published after 2011. Findings from the current review suggest the reporting of exercise intervention adherence to all four FITT prescription components requires the greatest improvement. The goal of adopting this style of intervention reporting is to facilitate translation into clinical practice, while also ensuring interventions are appropriately designed and monitored to maximize efficacy.

\section{Supplementary Information}

The online version contains supplementary material available at https://doi. org/10.1186/s12885-021-08701-y.

Additional file 1: Table S1. Description of studies.

\section{Acknowledgements}

Not applicable.

\section{Authors' contributions}

KWS and KC conceived of the original review. SNS conceived of the update. KB, SNS, MM, KZ and JK screened references and extracted all data. KB performed the statistical analysis and drafted the manuscript. All authors critically reviewed the manuscript and provided final approval.
Funding

None declared.

Availability of data and materials

The datasets used and/or analyzed during the current study are available from the corresponding author on reasonable request.

\section{Declarations}

Ethics approval and consent to participate

Not applicable.

\section{Consent for publication}

Not applicable.

\section{Competing interests}

The authors declare that they have no competing interests.

\section{Author details}

${ }^{1}$ Mary MacKillop Institute for Health Research, Australian Catholic University, Melbourne, Victoria, Australia. ${ }^{2}$ Department of Health Research Methods, Evidence and Impact, McMaster University, Hamilton, Ontario, Canada. ${ }^{3}$ Rehabilitation Sciences, University of British Columbia, Vancouver, British Columbia, Canada. ${ }^{4}$ Knight Cancer Institute, Oregon Health \& Science University, Portland, OR, USA. ${ }^{5}$ Department of Physical Therapy, University of British Columbia, 212-2177 Wesbrook Mall, Vancouver, BC V6T 1Z3, Canada.

Received: 7 May 2021 Accepted: 16 August 2021

Published online: 05 November 2021

\section{References}

1. Cormie P, Zopf EM, Zhang X, Schmitz KH. The impact of exercise on cancer mortality, recurrence, and treatment-related adverse effects. Epidemiol Rev. 2017;39(1):71-92.

2. Campbell KL, Winters-Stone KM, Wiskemann J, May AM, Schwartz AL, Courneya KS, et al. Exercise guidelines for cancer survivors: consensus statement from international multidisciplinary roundtable. Med Sci Sports Exerc. 2019;51(11):2375-90.

3. Furmaniak AC, Menig M, Markes MH. Exercise for women receiving adjuvant therapy for breast cancer. Cochrane Database Syst Rev. 2016;9:CD005001.

4. Meneses-Echavez JF, Gonzalez-Jimenez E, Ramirez-Velez R. Effects of supervised exercise on cancer-related fatigue in breast cancer survivors: a systematic review and meta-analysis. BMC Cancer. 2015;15(1):77.

5. Lahart IM, Metsios GS, Nevill AM, Carmichael AR. Physical activity for women with breast cancer after adjuvant therapy. Cochrane Database Syst Rev. 2018:1:CD011292.

6. Gardner JR, Livingston PM, Fraser SF. Effects of exercise on treatmentrelated adverse effects for patients with prostate cancer receiving androgen-deprivation therapy: a systematic review. J Clin Oncol. 2014;32(4): 335-46.

7. Vashistha V, Singh B, Kaur S, Prokop LJ, Kaushik D. The effects of exercise on fatigue, quality of life, and psychological function for men with prostate cancer: systematic review and meta-analyses. Eur Urol Focus. 2016;2(3):284-95.

8. Baguley BJ, Bolam KA, Wright ORL, Skinner TL. The effect of nutrition therapy and exercise on cancer-related fatigue and quality of life in men with prostate cancer: a systematic review. Nutrients. 2017;9(9):1003.

9. Heywood R, McCarthy AL, Skinner TL. Safety and feasibility of exercise interventions in patients with advanced cancer: a systematic review. Support Care Cancer. 2017;25(10):3031-50.

10. Dittus KL, Gramling RE, Ades PA. Exercise interventions for individuals with advanced cancer: a systematic review. Prev Med. 2017;104:124-32.

11. Sasso JP, Eves ND, Christensen JF, Koelwyn GJ, Scott J, Jones LW. A framework for prescription in exercise-oncology research. J Cachexia Sarcopenia Muscle. 2015;6(2):115-24.

12. Fairman CM, Zourdos MC, Helms ER, Focht BC. A scientific rationale to improve resistance training prescription in exercise oncology. Sports Med. 2017:47(8):1457-65.

13. Kirkham AA, Bonsignore A, Bland KA, McKenzie DC, Gelmon KA, Van Patten $\mathrm{CL}$, et al. Exercise prescription and adherence for breast cancer: one size does not FITT all. Med Sci Sports Exerc. 2018;50(2):177-86. 
14. Kirkham AA, Bland KA, Zucker DS, Bovard J, Shenkier T, McKenzie DC, et al. "Chemotherapy-periodized" exercise to accommodate for cyclical variation in fatigue. Med Sci Sports Exerc. 2020;52(2):278-86.

15. Campbell KL, Neil SE, Winters-Stone KM. Review of exercise studies in breast cancer survivors: attention to principles of exercise training. Br J Sports Med. 2012;46(13):909-16.

16. Winters-Stone KM, Neil SE, Campbell KL. Attention to principles of exercise training: a review of exercise studies for survivors of cancers other than breast. Br J Sports Med. 2014;48(12):987-95.

17. Neil-Sztramko SE, Winters-Stone KM, Bland KA, Campbell KL. Updated systematic review of exercise studies in breast cancer survivors: attention to the principles of exercise training. Br J Sports Med. 2019; 53(8):504-12.

18. Neil-Sztramko SE, Medysky ME, Campbell KL, Bland KA, Winters-Stone KM. Attention to the principles of exercise training in exercise studies on prostate cancer survivors: a systematic review. BMC Cancer. 2019;19(1):321.

19. Chang PH, Lai YH, Shun SC, Lin LY, Chen ML, Yang Y, et al. Effects of a walking intervention on fatigue-related experiences of hospitalized acute myelogenous leukemia patients undergoing chemotherapy: a randomized controlled trial. J Pain Symptom Manag. 2008;35(5):524-34.

20. Dimeo FC, Thomas F, Raabe-Menssen C, Propper F, Mathias M. Effect of aerobic exercise and relaxation training on fatigue and physical performance of cancer patients after surgery. A randomised controlled trial. Support Care Cancer. 2004;12(11):774-9.

21. Dimeo FC, Tilmann MH, Bertz H, Kanz L, Mertelsmann R, Keul J. Aerobic exercise in the rehabilitation of cancer patients after high dose chemotherapy and autologous peripheral stem cell transplantation. Cancer. 1997;79(9):1717-22.

22. Na YM, Kim MY, Kim YK, Ha YR, Yoon DS. Exercise therapy effect on natural killer cell cytotoxic activity in stomach cancer patients after curative surgery. Arch Phys Med Rehabil. 2000;81(6):777-9.

23. McNeely ML, Parliament M, Courneya KS, Seikaly H, Jha N, Scrimger $R$, et al. A pilot study of a randomized controlled trial to evaluate the effects of progressive resistance exercise training on shoulder dysfunction caused by spinal accessory neurapraxia/neurectomy in head and neck cancer survivors. Head Neck. 2004;26(6):518-30.

24. Donnelly CM, Blaney JM, Lowe-Strong A, Rankin JP, Campbell A, McCrumGardner $E_{\text {, et }}$ al. A randomised controlled trial testing the feasibility and efficacy of a physical activity behavioural change intervention in managing fatigue with gynaecological cancer survivors. Gynecol Oncol. 2011;122(3): 618-24

25. Courneya KS, Sellar CM, Stevinson C, McNeely ML, Peddle CJ, Friedenreich $\mathrm{CM}$, et al. Randomized controlled trial of the effects of aerobic exercise on physical functioning and quality of life in lymphoma patients. J Clin Oncol. 2009;27(27):4605-12

26. Adamsen L, Quist M, Andersen C, Moller T, Herrstedt J, Kronborg D, et al. Effect of a multimodal high intensity exercise intervention in cancer patients undergoing chemotherapy: randomised controlled trial. BMJ. 2009; 339:b3410.

27. Courneya KS, Friedenreich CM, Franco-Villalobos C, Crawford JJ, Chua N, Basi $\mathrm{S}$, et al. Effects of supervised exercise on progression-free survival in lymphoma patients: an exploratory follow-up of the HELP trial. Cancer Causes Control. 2015;26(2):269-76.

28. Courneya KS, Forbes CC, Trinh L, Sellar CM, Friedenreich CM, Reiman T. Patient satisfaction with participation in a randomized exercise trial: effects of randomization and a usual care posttrial exercise program. Clin Trials. 2013;10(6):959-66.

29. Courneya KS, Stevinson C, McNeely ML, Sellar CM, Friedenreich CM, PeddleMcIntyre CJ, et al. Effects of supervised exercise on motivational outcomes and longer-term behavior. Med Sci Sports Exerc. 2012;44(3):542-9.

30. Courneya KS, Stevinson C, McNeely ML, Sellar CM, Friedenreich CM, PeddleMclntyre CJ, et al. Predictors of follow-up exercise behavior 6 months after a randomized trial of supervised exercise training in lymphoma patients. Psychooncology. 2012;21(10):1124-31.

31. Courneya KS, Sellar CM, Trinh L, Forbes CC, Stevinson C, McNeely ML, et al. A randomized trial of aerobic exercise and sleep quality in lymphoma patients receiving chemotherapy or no treatments. Cancer Epidemiol Biomark Prev. 2012;21(6):887-94.

32. Donnelly CM, Lowe-Strong A, Rankin JP, Campbell A, Blaney JM, Gracey $\mathrm{JH}$. A focus group study exploring gynecological cancer survivors' experiences and perceptions of participating in a RCT testing the efficacy of a home-based physical activity intervention. Support Care Cancer. 2013;21(6):1697-708.

33. Andersen C, Rorth $M$, Ejlertsen B, Stage M, Moller T, Midtgaard J, et al. The effects of a six-week supervised multimodal exercise intervention during chemotherapy on cancer-related fatigue. Eur J Oncol Nurs. 2013;17(3):331-9.

34. Arbane G, Tropman D, Jackson D, Garrod R. Evaluation of an early exercise intervention after thoracotomy for non-small cell lung cancer (NSCLC), effects on quality of life, muscle strength and exercise tolerance: randomised controlled trial. Lung Cancer. 2011;71(2):229-34.

35. Backman MM, Wengstrom Y, Johansson B, Skoldengen I, Borjesson J, Tarnbro S, et al. A randomized pilot study with daily walking during adjuvant chemotherapy for patients with breast and colorectal cancer. Acta Oncol. 2014;53(4):510-20.

36. Capozzi LC, McNeely ML, Lau HY, Reimer RA, Giese-Davis J, Fung TS, et al. Patient-reported outcomes, body composition, and nutrition status in patients with head and neck cancer. Results from an exploratory randomized controlled exercise trial. Cancer. 2016;122(8):1185-200.

37. Christensen JF, Jones LW, Tolver A, Jorgensen LW, Andersen JL, Adamsen L, et al. Safety and efficacy of resistance training in germ cell cancer patients undergoing chemotherapy: a randomized controlled trial. Br J Cancer. 2014; 111(1):8-16.

38. Grote M, Maihofer C, Weigl M, Davies-Knorr P, Belka C. Progressive resistance training in cachectic head and neck cancer patients undergoing radiotherapy: a randomized controlled pilot feasibility trial. Radiat Oncol. 2018;13(1):215.

39. Hammer MJ, Eckardt P, Cartwright F, Miaskowski C. Prescribed walking for glycemic control and symptom management in patients without diabetes undergoing chemotherapy. Nurs Res. 2021;70(1):6-14.

40. Kamel FH, Basha MA, Alsharidah AS, Salama AB. Resistance training impact on mobility, muscle strength and lean mass in pancreatic cancer cachexia: a randomized controlled trial. Clin Rehabil. 2020;34(11):1391-9.

41. Lin KY, Shun SC, Lai YH, Liang JT, Tsauo JY. Comparison of the effects of a supervised exercise program and usual care in patients with colorectal cancer undergoing chemotherapy. Cancer Nurs. 2014;37(2):E21-9.

42. Moller T, Lillelund C, Andersen C, Bloomquist K, Christensen KB, Ejlertsen B, et al. The challenge of preserving cardiorespiratory fitness in physically inactive patients with colon or breast cancer during adjuvant chemotherapy: a randomised feasibility study. BMJ Open Sport Exerc Med. 2015;1(1):e000021.

43. Mustian KM, Sprod LK, Palesh OG, Peppone LJ, Janelsins MC, Mohile SG, et al. Exercise for the management of side effects and quality of life among cancer survivors. Curr Sports Med Rep. 2009:8(6):325-30.

44. Rogers LQ, Anton PM, Fogleman A, Hopkins-Price P, Verhulst S, Rao K, et al. Pilot, randomized trial of resistance exercise during radiation therapy for head and neck cancer. Head Neck. 2013;35(8):1178-88.

45. Samuel SR, Maiya GA, Babu AS, Vidyasagar MS. Effect of exercise training on functional capacity \& quality of life in head \& neck cancer patients receiving chemoradiotherapy. Indian J Med Res. 2013;137(3):515-20.

46. Samuel SR, Maiya AG, Fernandes DJ, Guddattu V, Saxena PUP, Kurian JR, et al. Effectiveness of exercise-based rehabilitation on functional capacity and quality of life in head and neck cancer patients receiving chemoradiotherapy. Support Care Cancer. 2019;27(10):3913-20.

47. Sandmael JA, Bye A, Solheim TS, Stene GB, Thorsen L, Kaasa S, et al. Feasibility and preliminary effects of resistance training and nutritional supplements during versus after radiotherapy in patients with head and neck cancer: a pilot randomized trial. Cancer. 2017;123(22):4440-8.

48. Stuecher K, Bolling C, Vogt L, Niederer D, Schmidt K, Dignass A, et al. Exercise improves functional capacity and lean body mass in patients with gastrointestinal cancer during chemotherapy: a single-blind RCT. Support Care Cancer. 2019;27(6):2159-69.

49. Van Vulpen JK, Velthuis MJ, Steins Bisschop CN, Travier N, Van Den Buijs BJ, Backx FJ, et al. Effects of an exercise program in colon cancer patients undergoing chemotherapy. Med Sci Sports Exerc. 2016;48(5):767-75.

50. Vigario Pdos S, Chachamovitz DS, Cordeiro MF, Teixeira Pde F, de Castro CL, de Oliveira FP, et al. Effects of physical activity on body composition and fatigue perception in patients on thyrotropin-suppressive therapy for differentiated thyroid carcinoma. Thyroid. 2011;21(7):695-700.

51. Xu YJ, Cheng JC, Lee JM, Huang PM, Huang GH, Chen CC. A walk-andeat intervention improves outcomes for patients with esophageal cancer undergoing neoadjuvant chemoradiotherapy. Oncologist. 2015; 20(10):1216-22. 
52. Yen CJ, Hung CH, Kao CL, Tsai WM, Chan SH, Cheng HC, et al. Multimodal exercise ameliorates exercise responses and body composition in head and neck cancer patients receiving chemotherapy. Support Care Cancer. 2019; 27(12):4687-95.

53. Zhao SG, Alexander NB, Djuric Z, Zhou J, Tao Y, Schipper M, et al. Maintaining physical activity during head and neck cancer treatment: results of a pilot controlled trial. Head Neck. 2016;38(Suppl 1):E1086-96.

54. Courneya KS, Friedenreich CM, Quinney HA, Fields AL, Jones LW, Fairey AS A randomized trial of exercise and quality of life in colorectal cancer survivors. Eur J Cancer Care (Engl). 2003;12(4):347-57.

55. DeNysschen CA, Brown JK, Cho MH, Dodd MJ. Nutritional symptom and body composition outcomes of aerobic exercise in women with breast cancer. Clin Nurs Res. 2011;20(1):29-46.

56. Edvardsen E, Skjonsberg OH, Holme I, Nordsletten L, Borchsenius F, Anderssen SA. High-intensity training following lung cancer surgery: a randomised controlled trial. Thorax. 2015;70(3):244-50.

57. Granger CL, Chao C, McDonald CF, Berney S, Denehy L. Safety and feasibility of an exercise intervention for patients following lung resection: a pilot randomized controlled trial. Integr Cancer Ther. 2013;12(3):213-24.

58. Hoffman AJ, Brintnall RA, Given BA, von Eye A, Jones LW, Brown JK. Using perceived self-efficacy to improve fatigue and fatigability in postsurgical lung cancer patients: a pilot randomized controlled trial. Cancer Nurs. 2017; 40(1):1-12.

59. Kaibori M, Ishizaki M, Matsui K, Nakatake R, Yoshiuchi S, Kimura Y, et al. Perioperative exercise for chronic liver injury patients with hepatocellular carcinoma undergoing hepatectomy. Am J Surg. 2013;206(2):202-9.

60. Onerup A, Thorn SE, Angenete E, Bock D, Gryback Gillheimer E, Haglind E, et al. Effects of a home-based exercise program on the insulin-like growth factor axis in patients operated for colorectal cancer in Sweden: results from the randomised controlled trial PHYSSURG-C. Growth Hormon IGF Res. 2020;51:27-33.

61. Quist M, Sommer MS, Vibe-Petersen J, Staerkind MB, Langer SW, Larsen $K R$, et al. Early initiated postoperative rehabilitation reduces fatigue in patients with operable lung cancer: a randomized trial. Lung Cancer. 2018;126:125-32.

62. Salhi B, Haenebalcke C, Perez-Bogerd S, Nguyen MD, Ninane V, Malfait TL, et al. Rehabilitation in patients with radically treated respiratory cancer: a randomised controlled trial comparing two training modalities. Lung Cancer. 2015;89(2):167-74.

63. Sommer MS, Trier K, Vibe-Petersen J, Missel M, Christensen M, Larsen KR, et al. Perioperative rehabilitation in operable lung cancer patients (PROLUCA): a feasibility study. Integr Cancer Ther. 2016;15(4):455-66.

64. Stigt JA, Uil SM, van Riesen SJ, Simons FJ, Denekamp M, Shahin GM, et al. A randomized controlled trial of postthoracotomy pulmonary rehabilitation in patients with resectable lung cancer. J Thorac Oncol. 2013;8(2):214-21.

65. Adams SC, DeLorey DS, Davenport MH, Stickland MK, Fairey AS, North S, et al. Effects of high-intensity aerobic interval training on cardiovascular disease risk in testicular cancer survivors: a phase 2 randomized controlled trial. Cancer. 2017;123(20):4057-65.

66. Arbane G, Douiri A, Hart N, Hopkinson NS, Singh S, Speed C, et al. Effect of postoperative physical training on activity after curative surgery for nonsmall cell lung cancer: a multicentre randomised controlled trial. Physiotherapy. 2014;100(2):100-7.

67. Bourke L, Thompson G, Gibson DJ, Daley A, Crank H, Adam I, et al. Pragmatic lifestyle intervention in patients recovering from colon cancer: a randomized controlled pilot study. Arch Phys Med Rehabil. 2011;92(5):749-55.

68. Brocki BC, Andreasen J, Nielsen LR, Nekrasas V, Gorst-Rasmussen A, Westerdahl E. Short and long-term effects of supervised versus unsupervised exercise training on health-related quality of life and functional outcomes following lung cancer surgery - a randomized controlled trial. Lung Cancer. 2014;83(1):102-8.

69. Brown JC, Troxel AB, Ky B, Damjanov N, Zemel BS, Rickels MR, et al. Doseresponse effects of aerobic exercise among colon cancer survivors: a randomized phase II trial. Clin Colorectal Cancer. 2017;17(1):32-40.

70. Cavalheri V, Jenkins S, Cecins N, Gain K, Phillips MJ, Sanders LH, et al. Exercise training for people following curative intent treatment for nonsmall cell lung cancer: a randomized controlled trial. Braz J Phys Ther. 2017; 21(1):58-68.

71. Chang YL, Tsai YF, Hsu CL, Chao YK, Hsu CC, Lin KC. The effectiveness of a nurse-led exercise and health education informatics program on exercise capacity and quality of life among cancer survivors after esophagectomy: a randomized controlled trial. Int J Nurs Stud. 2020;101:103418.

72. Christensen JF, Sundberg A, Osterkamp J, Thorsen-Streit S, Nielsen AB, Olsen $\mathrm{CK}$, et al. Interval walking improves glycemic control and body composition after cancer treatment: a randomized controlled trial. J Clin Endocrinol Metab. 2019;104(9):3701-12.

73. Crawford JJ, Vallance JK, Holt NL, Bell GJ, Steed H, Courneya KS. A pilot randomized, controlled trial of a wall climbing intervention for gynecologic cancer survivors. Oncol Nurs Forum. 2017;44(1):77-86.

74. Devin JL, Sax AT, Hughes GI, Jenkins DG, Aitken JF, Chambers SK, et al. The influence of high-intensity compared with moderate-intensity exercise training on cardiorespiratory fitness and body composition in colorectal cancer survivors: a randomised controlled trial. J Cancer Surviv. 2016;10(3): 467-79

75. Devin JL, Jenkins DG, Sax AT, Hughes Gl, Aitken JF, Chambers SK, et al. Cardiorespiratory fitness and body composition responses to different intensities and frequencies of exercise training in colorectal cancer survivors. Clin Colorectal Cancer. 2018;17(2):e269-79.

76. Gehring K, Kloek CJ, Aaronson NK, Janssen KW, Jones LW, Sitskoorn MM, et al. Feasibility of a home-based exercise intervention with remote guidance for patients with stable grade II and III gliomas: a pilot randomized controlled trial. Clin Rehabil. 2018;32(3):352-66.

77. Hausmann F, Iversen W, Kristoffersen M, Gundersen H, Johannsson E, Vika $M$. Combined aerobic and resistance training improves physical capacity in women treated for gynecological cancer. Support Care Cancer. 2018;26(10): 3389-96.

78. Lee DH, Kim JY, Lee MK, Lee C, Min JH, Jeong DH, et al. Effects of a 12-week home-based exercise program on the level of physical activity, insulin, and cytokines in colorectal cancer survivors: a pilot study. Support Care Cancer. 2013;21(9):2537-45

79. Lee MK, Kim JY, Kim DI, Kang DW, Park JH, Ahn KY, et al. Effect of homebased exercise intervention on fasting insulin and Adipocytokines in colorectal cancer survivors: a randomized controlled trial. Metabolism. 2017; 76:23-31.

80. Lee MK, Kim NK, Jeon JY. Effect of the 6-week home-based exercise program on physical activity level and physical fitness in colorectal cancer survivors: a randomized controlled pilot study. PLoS One. 2018;13(4): e0196220.

81. Lonbro S, Dalgas U, Primdahl H, Johansen J, Nielsen $J$, Aagaard P, et al. Progressive resistance training rebuilds lean body mass in head and neck cancer patients after radiotherapy--results from the randomized DAHANCA 25B trial. Radiother Oncol. 2013;108(2):314-9.

82. Martin EA, Battaglini CL, Naumann F. Higher-intensity exercise results in more sustainable improvements for VO2peak for breast and prostate cancer survivors. Oncol Nurs Forum. 2015;42(3):241-9.

83. Mascherini G, Ringressi MN, Castizo-Olier J, Badicu G, Irurtia A, Stefani L, et al. Preliminary results of an exercise program after laparoscopic resective colorectal cancer surgery in non-metastatic adenocarcinoma: a pilot study of a randomized control trial. Medicina (Kaunas). 2020;56(2):78.

84. McNeely ML, Parliament MB, Seikaly H, Jha N, Magee DJ, Haykowsky MJ, et al. Effect of exercise on upper extremity pain and dysfunction in head and neck cancer survivors: a randomized controlled trial. Cancer. 2008; 113(1):214-22

85. Messaggi-Sartor M, Marco E, Martinez-Tellez E, Rodriguez-Fuster A, Palomares C, Chiarella S, et al. Combined aerobic exercise and highintensity respiratory muscle training in patients surgically treated for nonsmall cell lung cancer: a pilot randomized clinical trial. Eur J Phys Rehabil Med. 2019;55(1):113-22.

86. Meyerhardt JA, Irwin ML, Jones LW, Zhang S, Campbell N, Brown JC, et al. Randomized phase II trial of exercise, metformin, or both on metabolic biomarkers in colorectal and breast cancer survivors. JNCI Cancer Spectrum. 2019;4(1):pkz096.

87. Nuri R, Moghaddasi M, Darvishi H, Izadpanah A. Effect of aerobic exercise on leptin and ghrelin in patients with colorectal cancer. J Cancer Res Ther. 2016;12(1):169-74

88. Pinto BM, Papandonatos GD, Goldstein MG, Marcus BH, Farrell N. Homebased physical activity intervention for colorectal cancer survivors. Psychooncology. 2013;22(1):54-64.

89. Porserud A, Sherif A, Tollback A. The effects of a physical exercise programme after radical cystectomy for urinary bladder cancer. A pilot randomized controlled trial. Clin Rehabil. 2014;28(5):451-9. 
90. Rossi A, Garber CE, Ortiz M, Shankar V, Goldberg GL, Nevadunsky NS Feasibility of a physical activity intervention for obese, socioculturally diverse endometrial cancer survivors. Gynecol Oncol. 2016;142(2):304-10.

91. Alibhai SM, Durbano S, Breunis H, Brandwein JM, Timilshina N, Tomlinson GA, et al. A phase II exercise randomized controlled trial for patients with acute myeloid leukemia undergoing induction chemotherapy. Leuk Res. 2015;39(11):1178-86

92. Baumann FT, Kraut L, Schüle K, Bloch W, Fauser AA. A controlled randomized study examining the effects of exercise therapy on patients undergoing haematopoietic stem cell transplantation. Bone Marrow Transplant. 2010;45(2):355-62

93. Baumann FT, Zopf EM, Nykamp E, Kraut L, Schüle K, Elter T, et al. Physical activity for patients undergoing an allogeneic hematopoietic stem cell transplantation: benefits of a moderate exercise intervention. Eur J Haematol. 2011:87(2):148-56.

94. Bryant AL, Deal AM, Battaglini CL, Phillips B, Pergolotti M, Coffman E, et al. The effects of exercise on patient-reported outcomes and performancebased physical function in adults with acute leukemia undergoing induction therapy: exercise and quality of life in acute leukemia (EQUAL). Integr Cancer Ther. 2018;17(2):263-70.

95. Coleman EA, Coon S, Hall-Barrow J, Richards K, Gaylor D, Stewart B. Feasibility of exercise during treatment for multiple myeloma. Cancer Nurs. 2003;26(5):410-9.

96. Coleman EA, Goodwin JA, Kennedy R, Coon SK, Richards K, Enderlin C, et al. Effects of exercise on fatigue, sleep, and performance: a randomized trial. Oncol Nurs Forum. 2012;39(5):468-77.

97. Duregon F, Gobbo S, Bullo V, Roma E, Vendramin B, Bergamo M, Bocalini DS, Di Blasio A, Cugusi L, Neunhaeuserer D, et al. Exercise prescription and tailored physical activity intervention in onco-hematology inpatients, a personalized bedside approach to improve clinical best practice. Hematol Oncol. 2019;37(3):277-84.

98. Jarden M, Nelausen K, Hovgaard D, Boesen E, Adamsen L. The effect of a multimodal intervention on treatment-related symptoms in patients undergoing hematopoietic stem cell transplantation: a randomized controlled trial. J Pain Symptom Manag. 2009;38(2):174-90.

99. Larsen RF, Jarden M, Minet LR, Frolund UC, Abildgaard N. Supervised and home-based physical exercise in patients newly diagnosed with multiple myeloma-a randomized controlled feasibility study. Pilot Feasibility Stud. 2019;5(1):130.

100. Oechsle K, Aslan Z, Suesse Y, Jensen W, Bokemeyer C, de Wit M. Multimodal exercise training during myeloablative chemotherapy: a prospective randomized pilot trial. Support Care Cancer. 2014;22(1):63-9.

101. Santa Mina D, Dolan LB, Lipton JH, Au D, Perez EC, Franzese A, et al. Exercise before, during, and after hospitalization for allogeneic hematological stem cell transplant: a feasibility randomized controlled trial. J Clin Med. 2020;9(6):1854.

102. Streckmann F, Kneis S, Leifert JA, Baumann FT, Kleber M, lhorst G, et al. Exercise program improves therapy-related side-effects and quality of life in lymphoma patients undergoing therapy. Ann Oncol. 2014;25(2):493-9.

103. Wehrle A, Kneis S, Dickhuth HH, Gollhofer A, Bertz H. Endurance and resistance training in patients with acute leukemia undergoing induction chemotherapya randomized pilot study. Support Care Cancer. 2019;27(3):1071-9.

104. Koutoukidis DA, Land J, Hackshaw A, Heinrich M, McCourt O, Beeken RJ, et al. Fatigue, quality of life and physical fitness following an exercise intervention in multiple myeloma survivors (MASCOT): an exploratory randomised phase 2 trial utilising a modified Zelen design. Br J Cancer. 2020;123(2):187-95.

105. Mello M, Tanaka C, Dulley FL. Effects of an exercise program on muscle performance in patients undergoing allogeneic bone marrow transplantation. Bone Marrow Transplant. 2003;32(7):723-8.

106. Wiskemann J, Dreger P, Schwerdtfeger R, Bondong A, Huber G, Kleindienst $\mathrm{N}$, et al. Effects of a partly self-administered exercise program before, during, and after allogeneic stem cell transplantation. Blood. 2011;117(9):2604-13.

107. Alibhai SM, O'Neill S, Fisher-Schlombs K, Breunis H, Timilshina N, Brandwein $J M$, et al. A pilot phase II RCT of a home-based exercise intervention for survivors of AML. Support Care Cancer. 2014;22(4):881-9.

108. Furzer BJ, Ackland TR, Wallman KE, Petterson AS, Gordon SM, Wright KE, et al. A randomised controlled trial comparing the effects of a 12-week supervised exercise versus usual care on outcomes in haematological cancer patients. Support Care Cancer. 2016;24(4):1697-707.
109. Hacker ED, Larson J, Kujath A, Peace D, Rondelli D, Gaston L. Strength training following hematopoietic stem cell transplantation. Cancer Nurs. 2011;34(3):238-49.

110. Hacker ED, Collins E, Park C, Peters T, Patel P, Rondelli D. Strength training to enhance early recovery after hematopoietic stem cell transplantation. Biol Blood Marrow Transplant. 2017;23(4):659-69.

111. Jarden M, Moller T, Kjeldsen L, Birgens H, Christensen JF, Bang Christensen $\mathrm{K}$, et al. Patient activation through counseling and exercise--acute leukemia (PACE-AL)--a randomized controlled trial. BMC Cancer. 2013;13(446):446.

112. Knols RH, de Bruin ED, Uebelhart D, Aufdemkampe G, Schanz U, StennerLiewen $F$, et al. Effects of an outpatient physical exercise program on hematopoietic stem-cell transplantation recipients: a randomized clinical trial. Bone Marrow Transplant. 2011;46(9):1245-55.

113. Persoon S, ChinAPaw MJM, Buffart LM, Liu RDK, Wijermans P, Koene HR, et al. Randomized controlled trial on the effects of a supervised high intensity exercise program in patients with a hematologic malignancy treated with autologous stem cell transplantation: Results from the EXIST study. PloS One. 2017;12(7):e0181313.

114. Shelton ML, Lee JQ, Morris GS, Massey PR, Kendall DG, Munsell MF, et al. A randomized control trial of a supervised versus a self-directed exercise program for allogeneic stem cell transplant patients. Psychooncology. 2009; 18(4):353-9.

115. Arrieta H, Astrugue C, Regueme S, Durrieu J, Maillard A, Rieger A, et al. Effects of a physical activity programme to prevent physical performance decline in onco-geriatric patients: a randomized multicentre trial. J Cachexia Sarcopenia Muscle. 2019;10(2):287-97.

116. Griffith K, Wenzel J, Shang J, Thompson C, Stewart K, Mock V. Impact of a walking intervention on cardiorespiratory fitness, self-reported physical function, and pain in patients undergoing treatment for solid tumors. Cancer. 2009;115(20):4874-84

117. Marechal R, Fontvieille A, Parent-Roberge H, Fulop T, Riesco E, Pavic M, et al. Effect of a mixed-exercise program on physical capacity and sedentary behavior in older adults during cancer treatments. Aging Clin Exp Res. 2019; 31(11):1583-9.

118. Peterson BM, Johnson C, Case KR, Shackelford DYK, Brown JM, Lalonde TL, et al. Feasibility of a combined aerobic and cognitive training intervention on cognitive function in cancer survivors: a pilot investigation. Pilot Feasibility Stud. 2018;4(50):50.

119. Sturm I, Baak J, Storek B, Traore A, Thuss-Patience P. Effect of dance on cancer-related fatigue and quality of life. Support Care Cancer. 2014;22(8): 2241-9.

120. Wenzel JA, Griffith KA, Shang J, Thompson CB, Hedlin H, Stewart KJ, et al. Impact of a home-based walking intervention on outcomes of sleep quality, emotional distress, and fatigue in patients undergoing treatment for solid tumors. Oncologist. 2013;18(4):476-84.

121. Courneya KS, Friedenreich CM, Sela RA, Quinney HA, Rhodes RE, Handman M. The group psychotherapy and home-based physical exercise (grouphope) trial in cancer survivors: physical fitness and quality of life outcomes. Psychooncology. 2003;12(4):357-74.

122. Courneya KS, Jones LW, Peddle CJ, Sellar CM, Reiman T, Joy AA, et al. Effects of aerobic exercise training in anemic cancer patients receiving darbepoetin alfa: a randomized controlled trial. Oncologist. 2008;13(9):1012-20.

123. Irwin ML, Cartmel B, Harrigan M, Li F, Sanft T, Shockro L, et al. Effect of the LIVESTRONG at the YMCA exercise program on physical activity, fitness, quality of life, and fatigue in cancer survivors. Cancer. 2017; 123(7):1249-58.

124. Mayo NE, Moriello C, Scott SC, Dawes D, Auais M, Chasen M. Pedometerfacilitated walking intervention shows promising effectiveness for reducing cancer fatigue: a pilot randomized trial. Clin Rehabil. 2014;28(12):1198-209.

125. Schuler MK, Hentschel L, Kisel W, Kramer M, Lenz F, Hornemann B, et al. Impact of different exercise programs on severe fatigue in patients undergoing anticancer treatment-a randomized controlled trial. J Pain Symptom Manag. 2017:53(1):57-66.

126. Schwartz AL, Winters-Stone K. Effects of a 12-month randomized controlled trial of aerobic or resistance exercise during and following cancer treatment in women. Phys Sportsmed. 2009;37(3):62-7.

127. Broderick JM, Guinan E, Kennedy MJ, Hollywood D, Courneya KS, CulosReed SN, et al. Feasibility and efficacy of a supervised exercise intervention in de-conditioned cancer survivors during the early survivorship phase: the PEACH trial. J Cancer Surviv. 2013;7(4):551-62. 
128. Burnham TR, Wilcox A. Effects of exercise on physiological and psychological variables in cancer survivors. Med Sci Sports Exerc. 2002; 34(12):1863-7.

129. Jones LW, Douglas PS, Khouri MG, Mackey JR, Wojdyla D, Kraus WE, et al. Safety and efficacy of aerobic training in patients with cancer who have heart failure: an analysis of the HF-ACTION randomized trial. J Clin Oncol. 2014;32(23):2496-502.

130. Kampshoff CS, Chinapaw MJ, Brug J, Twisk JW, Schep G, Nijziel MR, et al Randomized controlled trial of the effects of high intensity and low-tomoderate intensity exercise on physical fitness and fatigue in cancer survivors: results of the Resistance and Endurance exercise After ChemoTherapy (REACT) study. BMC Med. 2015;13(275):275.

131. Kneis S, Wehrle A, Muller J, Maurer C, Ihorst G, Gollhofer A, et al. It's never too late - balance and endurance training improves functional performance, quality of life, and alleviates neuropathic symptoms in cancer survivors suffering from chemotherapy-induced peripheral neuropathy: results of a randomized controlled trial. BMC Cancer. 2019;19(1):414.

132. Knobf MT, Jeon S, Smith B, Harris L, Thompson S, Stacy MR, et al. The Yale fitness intervention trial in female cancer survivors: cardiovascular and physiological outcomes. Heart Lung. 2017;46(5):375-81.

133. LaStayo PC, Marcus RL, Dibble LE, Smith SB, Beck SL. Eccentric exercise versus usual-care with older cancer survivors: the impact on muscle and mobility--an exploratory pilot study. BMC Geriatr. 2011;11:5.

134. Midtgaard J, Christensen JF, Tolver A, Jones LW, Uth J, Rasmussen B, et al. Efficacy of multimodal exercise-based rehabilitation on physical activity, cardiorespiratory fitness, and patient-reported outcomes in cancer survivors: a randomized, controlled trial. Ann Oncol. 2013;24(9):2267-73.

135. Pisu M, Demark-Wahnefried W, Kenzik KM, Oster RA, Lin CP, Manne S, et al. A dance intervention for cancer survivors and their partners (RHYTHM). J Cancer Surviv. 2017;11(3):350-9.

136. Thorsen L, Skovlund E, Stromme SB, Hornslien K, Dahl AA, Fossa SD. Effectiveness of physical activity on cardiorespiratory fitness and healthrelated quality of life in young and middle-aged cancer patients shortly after chemotherapy. J Clin Oncol. 2005;23(10):2378-88.

137. Toohey K, Pumpa KL, Arnolda L, Cooke J, Yip D, Craft PS, et al. A pilot study examining the effects of low-volume high-intensity interval training and continuous low to moderate intensity training on quality of life, functional capacity and cardiovascular risk factors in cancer survivors. PeerJ. 2016;4:e2613.

138. Fairman CM, Nilsen TS, Newton RU, Taaffe DR, Spry N, Joseph D, et al. Reporting of resistance training dose, adherence, and tolerance in exercise oncology. Med Sci Sports Exerc. 2019;52(2):315-22.

139. Nilsen TS, Scott JM, Michalski M, Capaci C, Thomas S, Herndon JE 2nd, et al. Novel methods for reporting of exercise dose and adherence: an exploratory analysis. Med Sci Sports Exerc. 2018;50(6):1134-41.

140. Scott JM, lyengar NM, Nilsen TS, Michalski M, Thomas SM, Herndon J 2nd, et al. Feasibility, safety, and efficacy of aerobic training in pretreated patients with metastatic breast cancer: a randomized controlled trial. Cancer. 2018;124(12):2552-60.

141. Borg G. Borg's perceived exertion and pain scales. Champaign: Human Kinetics; 1998.

142. Fairman CM, LaFountain RL, Lucas AR, Focht BC. Monitoring resistance exercise intensity using ratings of perceived exertion in previously untrained patients with prostate cancer undergoing androgen deprivation therapy. J Strength Cond Res. 2018;32(5):1360-5.

143. Glasziou P, Meats $E$, Heneghan C, Shepperd S. What is missing from descriptions of treatment in trials and reviews? BMJ. 2008;336(7659):1472-4.

144. Meneses-Echavez JF, Rodriguez-Prieto I, Elkins M, Martinez-Torres J, Nguyen $L$, Bidonde J. Analysis of reporting completeness in exercise cancer trials: a systematic review. BMC Med Res Methodol. 2019;19(1):220.

145. Hoffmann TC, Glasziou PP, Boutron I, Milne R, Perera R, Moher D, et al. Better reporting of interventions: template for intervention description and replication (TIDieR) checklist and guide. BMJ. 2014;78(3):175-88.

146. Slade SC, Finnegan S, Dionne CE, Underwood M, Buchbinder R. The Consensus on Exercise Reporting Template (CERT) applied to exercise interventions in musculoskeletal trials demonstrated good rater agreement and incomplete reporting. J Clin Epidemiol. 2018;103:120-30.
147. Medysky ME, Bland KA, Neil-Sztramko SE, Campbell KL, Sullivan DR, WintersStone KM. Attention to the principles of exercise training in exercise studies of persons with lung cancer: a systematic review. J Aging Phys Act. 2021:111. https://doi.org/10.1123/japa.2020-0269.

148. Sweegers MG, Altenburg TM, Brug J, May AM, van Vulpen JK, Aaronson NK, et al. Effects and moderators of exercise on muscle strength, muscle function and aerobic fitness in patients with cancer: a meta-analysis of individual patient data. Br J Sports Med. 2019;53(13):812.

\section{Publisher's Note}

Springer Nature remains neutral with regard to jurisdictional claims in published maps and institutional affiliations.
Ready to submit your research? Choose BMC and benefit from:

- fast, convenient online submission

- thorough peer review by experienced researchers in your field

- rapid publication on acceptance

- support for research data, including large and complex data types

- gold Open Access which fosters wider collaboration and increased citations

- maximum visibility for your research: over $100 \mathrm{M}$ website views per year

At BMC, research is always in progress.

Learn more biomedcentral.com/submissions 